\title{
PENGARUH KEMIRINGAN POROS BALING-BALING TERHADAP KECEPATAN PERAHU KETINTING
}

\author{
M. Nur Habib ${ }^{1 *}$, E. R. de Fretes ${ }^{2}$, S. T. A. Lekatompessy ${ }^{3}$ \\ ${ }^{1}$ Jurusan Teknik Perkapalan Fakultas Teknik Universitas Pattimura, Ambon97233 \\ *Email: nurkhabib1997@gmail.com \\ 2Jurusan Teknik Perkapalan Fakultas Teknik Universitas Pattimura, Ambon 97233 \\ Email: defretesera@gmail.com \\ 3Jurusan Teknik Perkapalan Fakultas Teknik Universitas Pattimura, Ambon 97233 \\ Email: sonja.lekatompessy@gmail.com
}

\begin{abstract}
Abstrak. Perahu ketinting dalam pengoperasiannya menggunakan propellerdengan mesin terletak diatas geladak. Posisi ini mengakibatkan propeller tercelup dengan membuat sudut tertentu, selain itu kedalaman propeller juga mempangaruhi kecepatan kapal. Fenomena ini merupakan sesuatu yang sangat penting untuk di teliti dengan tujuan mendapatkan kecepatan maksimum dalam kaitannya dengan sudut kemiringan propeller dan besarnya daya dorong maksimum yang dibutuhkan. Metode yang digunakan adalah metode eksperimental dimana model kapal dan propeller dibuat sesuai dengan skala yang diinginkan, dan seterusnya melakukan pengujian di towing tank. Hasil penguujian yang diperoleh yaitu kemiringan yang menciptakan kecepatan optimal perahu ketinting berada pada kemiringan $18^{\circ}$ dengan kecepatan $\mathrm{V}=5,05$ knot serta daya dorong maksimal PT= $13,15 \mathrm{~kW}$.
\end{abstract}

Kata kunci: Kemiringan Poros, Daya Dorong, Kecepatan. Kemiringan propeller, perahu ketinting

\begin{abstract}
Ketinting boat in operation using propeller with engine located on deck. This position resulted in the propeller dipping by making a certain angle, in addition the depth of the propeller also overlapped the speed of the ship.This phenomenon is something very important to be examined with the aim of obtaining maximum speed in relation to the angle of tilt of the propeller and the amount of maximum thrust required.The method used is an experimental method in which the model of the ship and propeller are made according to the desired scale, and so conduct testing on the towing tank.The test result obtained is a slope that creates the optimal speed of the ketinting boat is at a slope of $18^{\circ}$ with a speed of $V=5.05$ knots and a maximum thrust of PT = $13.15 \mathrm{~kW}$.
\end{abstract}

Keywords: Shaft Tilt, Thrust, Speed, propeller slope, ketinting boat

\section{PENDAHULUAN}

Pengoperasian perahu ketinting memiliki sistimpenggerak baling-baling,poros baling-baling merupakan salah satu bagian dari sistim penggerak kapal yang digerakan oleh mesin dan berfungsi untuk meneruskan gaya dorong. Putaran mesin ditransmisikan ke baling-baling melalui poros dengan posisi kemiringan tertentu kemudian dengan kemiringan poros yang digunakan untuk menentukan besar kecilnya gaya dorong yang merupakan fungsi dari daya dorong dan kecepatan. Pada sistim ini apabila baling- baling pada sudut tertentu tercelup sebahagian, maka daya dorong yang dihasilkanpun tidak terlalu besar, sedangkan pada saat baling-baling tercelup secara penuh daya dorong dan kecepatanpun jadi berubah dan seterusnya ampai dengan sudut yang besar maka daya dorong dan kecepatan makin kecil karena kosinus arah yang terjadi. Sehingga permasalahan yang terjadi adalah seberapa besar pengaruh kemiringan poros baling- baling terhadap daya dorong dan kecepatan perahu ketinting. 
Penggunaan kemiringan poros yang digunakan di lapangan adalah kemiringan $16^{\circ}$ dengan daya dorong $12,77 \mathrm{~kW}$ dan kecepatan 4,4 knot, dimana perahu memiliki kecepatan yang tidak maksimal dengan daya mesin yang maksimal, (Masroeri, Asianto,1999 \&studi kasus). Penggunaan kemiringan poros tidak memiliki standard pengoperasian, mereka hanya menggunakan tali atau kawat sebagai penahan beban poros balingbaling tanpa mengetahui berapa kemiringan poros baling-baling yang di gunakan, sehingga pengaruhnya terhadap daya dorong yang dihasilkan tidak maksimal, kecepatan perahu ketinting tidak stabil serta banyaknya bahan bakar yang digunakan dalam jarak pengoperasian tertentu tidak optimal, sehingga perlu dilakukan analisis dengan teliti.

\section{BAHAN DAN METODE}

\subsection{Prosedur Penelitian dan Persamaan}

Sabik dan Purwaka (2018) menjelaskan tentang aplikasi penggerak perahu ketinting, yang dilanjutkan oleh Windyandari dan Wahyudi 2011 yang sistem propulsi kapal ketinting dalam kaitannya dengandaya dorong, Abar et al (2018) menjelaskan tentang kemiringan hub dalam kaitannya dengan efisiensi baling-baling, munawir et al (2017) menngambarkan tentang pengaruh sudut kemiringan baling-naling pada perahu jukung terhadap daya dorong kapal. Dari penelitian-penelitian diatas, digunakan untuk kapal-kapal yang menggunakan mesin dalam bukan mesin ketinting yang letaknya di atas kapal, sehingga penelitian ini dilakukan untuk mesin yang berada di atas geladak kapal. Beberapa formulasi yang digunakan adalah :

$$
T=\frac{E H P}{(1-t) x V s}
$$

Dimana :

$$
\begin{array}{ll}
\text { EHP } & =\text { Effective Horse Power } \\
\mathrm{Vs} & =\text { Kecepatan Dinas } \\
\mathrm{t} & =\text { Trusth deduction factor } \\
\mathrm{T} & =\text { Gaya Dorong }
\end{array}
$$

Penelitian ini berlangsung di Rumah Tiga, Tulehu, Ureng, Seith dan Hitu, proses penelitian untuk mendapatkan data-data primer langsung pada objek perahu ketinting. Hasil penelitian kemudian dilakukan perhitungan dan simulasi di towing. Objek dalam penelitian ini adalah pengaruh kemiringan poros baling- baling perahu ketinting. Tipe penelitian ini adalah pengujian eksperimen pembuktian dengan menggunakan model yang diuji pada laboraturium towink tank. Penelitian ini merupakan penelitian eksperimen yang bertujuan mengetahui pengaruh kemiringan poros baling-baling terhadap kecepatan perahu ketinting. Rancangan penelitian menggunakan faktor variasi kemiringan $0^{\circ}, 2^{\circ}, 4^{\circ}, 6^{\circ}, 8^{\circ}, 10^{\circ}$, $12^{\circ}, 14^{\circ}, 16^{\circ}, 18^{\circ}, 20^{\circ}, 22^{\circ}, 24^{\circ}, 26^{\circ}, 28^{\circ}, 30^{\circ}$. Demikian dalam uji laboratorium dengan beberapa variasi yang ada diharapkan dari setiap hasil uji eksperimen variasi kemiringan tertentu dapat mempresentasikan waktu dan kecepatan maksimal terhadap pengaruh penggunaan kemiringan poros baling-baling.

Pengujian kecepatan model dan kecepatan putar mesin, dimana kecepatan yang diuji menggunakan variasi kemiringan poros balingbaling adalah $0.718 \mathrm{~m} / \mathrm{s}$ dan besar maksimal putaran mesin 1500 RPM, dengan variasi sudut kemiringan yang digunakan adalah $0^{\circ}, 2^{\circ}, 4^{\circ}, 6^{\circ}$, $8^{\circ}, 10^{\circ}, 12^{\circ}, 14^{\circ}, 16^{\circ}, 18^{\circ}, 20^{\circ}, 22^{\circ}, 24^{\circ}, 26^{\circ}, 28^{\circ}$, $30^{\circ}$, dengan keterangan kondisi di lapangan pada Gambar 1.
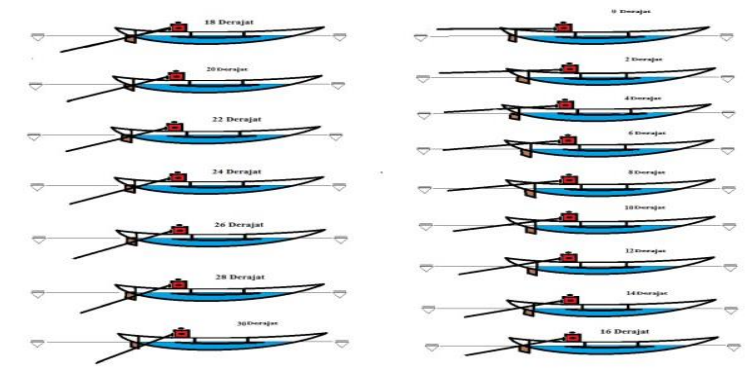

Gambar 1. Outlet Uji Coba Laboratorium

\subsection{Fasilitas Pengujian dan Model}

Adapun fasilitas yang digunakan untuk pengujian model adalah Tangki Uji (Towing Tank) dengan memiliki ukuran sebagai berikut:
a. Panjang : $90 \mathrm{~m}$
b. Lebar : $5 \mathrm{~m}$
c. Tinggi : $2,5 \mathrm{~m}$
d. Sarat air : $1,5 \mathrm{~m}$

Spesifikasi Model Perahu Ketinting
a. Panjang keseluruhan (Loa) $\quad: 0,70 \mathrm{~m}$
b. Panjng Garis air (Lwl) $\quad: 0,67 \mathrm{~m}$
c. Lebar (B) $\quad: 0,65 \mathrm{~m}$
d. Tinggi perahu ketinting $(\mathrm{H}) \quad: 0,50 \mathrm{~m}$
e. Tinggi sarat (T) $\quad: 0,30 \mathrm{~m}$
f. Koefisien Blok : 0,54
g. Luas Permukaan Basah (s) : 0,395 $\mathrm{m}^{2}$
h. Kecepatan $\quad: 0,718 \mathrm{~m} / \mathrm{s}$
i. Jenis Baling-baling $\quad: 2$ Sudu

\section{HASIL DAN PEMBAHASAN}

\subsection{Data Kapal}

Perahu ketinting yang digunakan sebagai subjek pada penelitian ini adalah yang berada di daerah sekitar Kota Ambon. Adapun spesifikasi dan ukuran pokok perahu ketinting. 
a. Panjang keseluruhan (Loa) $\quad: 7,0 \mathrm{~m}$

b. Panjng Garis air (Lwl) : $6,7 \mathrm{~m}$

c. Lebar (B)

$: 6,5 \mathrm{~m}$

d. Tinggi perahu ketinting $(\mathrm{H}) \quad: 0,50 \mathrm{~m}$

e. Tinggi sarat $(\mathrm{T})$

$: 0,30 \mathrm{~m}$

$: 0,54$

: 4,40 Knot

: GX 160

: 2 Sudu

: $2 \mathrm{~m}$

$: 16-20^{\circ}$

\subsection{Hasil Pengujian}

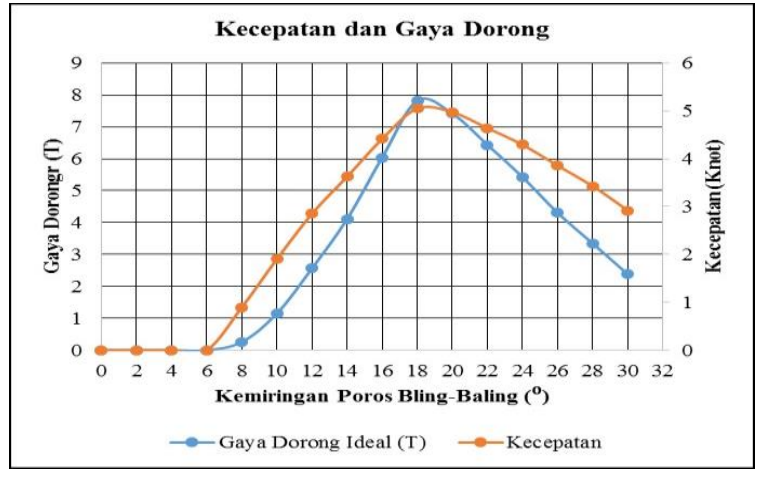

Gambar 2. Kecepatan dan Gaya Dorong

Gambar 2 menjelaskan hubungan antara kecepatan dan gaya dorong perahu ketinting yang dihasilkan dari penggunaan variasi kemiringan tertentu dan pengurangan kecepatan terhadap penggunaan kemiringan poros baling-baling perahu ketinting. Berdasarkan grafik di atas maka dapat disimpulkan bahwa penggunaan dari sudut kemiringan poros baling-baling $8^{0} 18^{\circ}$ perahu mengalami peningkatan yang continue, pada kemiringan $20^{\circ}-30^{\circ}$ perahu mengalami penurunan yang continue. Kemiringan poros baling-baling yang digunakan di lapangan berada pada sudut 16 o dengan kecepatan 4.4 knot dan gaya dorong 6,28 $\mathrm{kN}$, sedangkan kecepatan dan gaya dorong yang di teliti berada pada sudut $18^{\circ}$ dengan kecepatan 5.05 knot dan gaya dorong $8,21 \mathrm{kN}$.

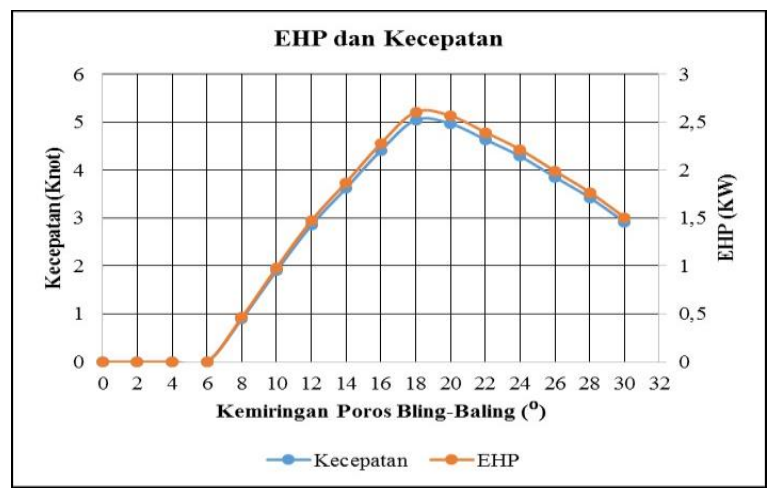

Gambar 3. EHP dan Kecepatan
Gambar 3 Menunjukkan hubungan antara kecepatan dan EHP perahu ketinting, dapat dilihat bahwa kecepatan tertentu EHP (Rtdinas x V) perahu berubah untuk menghasilkan daya motor perahu ketinting karena penggunaan variasi kemiringan poros baling-baling perahu ketinting yang digunakan dalam penelitian. Berdasaran perhitungan tabel diatas menunjukan bahwa kecepatan dan EHP perahu pada kemiringan poros baling-baling $8^{\circ}-18^{\circ}$ perahu mengalami peningkatan yang continue, dengan kecepatan dan gaya dorong terbesar pada kemiringan $18^{\circ} \mathrm{Pada}$ kemiringan poros baling-baling $20^{\circ}-30^{\circ}$ perahu mengalami penurunan yan continue. Menjelaskan hubungan antara kecepatan dan EHP perahu ketinting yang dihasilkan dari penggunaan variasi kemiringan tertentu dan pengurangan kecepatan terhadap penggunaan kemiringan poros balingbaling perahu ketinting. Berdasarkan grafik di atas maka dapat disimpulkan bahwa penggugnaan dari sudut kemiringan poros baling-baling 8 -18 perahu mengalami peningkatan yang continue, pada kemiringan 20-30 perahu mengalami penurunan yang continue. Kemiringan poros baling-baling yang digunakan di lapangan berada pada sudut 16 dengan kecepatan 4.4 knot dan EHP 2,27 kW, sedangkan kecepatan dan daya dorong yang di teliti berada pada sudut 18 dengan kecepatan 5.05 knot dan EHP 3,60 kW. Perubahan daya dorong dan kecepatan ${ }_{0}$ yang signifikan terjadi dari kemiringan poros $16^{0}-18$, dan pada puncaknya daya dorong dan kecepatan terhadap penggunaan kemiringan poros berada pada kemiringan poros 18, di karenakan perubahan terjadi pengaruh kemiringan poros berada pada kemiringan poros ideal dengan tinggi dan dalamnya poros baling-baling menyentuh permukaan air yang didefinisakan sebagai besar dan kecilnya nilai alfa ${ }^{\alpha}$ ) dan jarak (Fx) dan (t) adalah kriteria matching terbaik dari kemiringan poros yang digunakan

\section{KESIMPULAN}

Dari penelitian pengaruh kemiringan poros baling-baling terhadap daya dorong dan kecepatan yang telah dilakukan, kesimpulan yang dapat diambil sebagai berikut:

1. Daya dorong dan kecepatan perahu ketinting dipengaruhi oleh posisi kemirigan poros baling- baling yang digunakan.

2. Kemiringan poros baling-baling yang menghasilkan daya dorong maksimal perahu ketinting adalah pada kemiringan $18^{\circ}$ dengan daya dorong perahu ketinting sebesar $\mathrm{P}_{\mathrm{T}}=$ $13,15 \mathrm{~kW}$ dengan kecepatan Vs $=5,05$ knot. 


\section{DAFTAR PUSTAKA}

[1] Abar I.A.C., Utama I. P. dan Iqbal Muhammad, 2018. An Investigation in to the effect of slope angle Hub Cap Geometry against the efficiency of ship propeller in the presence of PBFC. Proceeding of Maritime Safety and Maritime installation, MSMI 2018 published by CSP

[2] Ahmad Munawir, Gatut Rubiono, Haris Mujianto, 2017. Studi Prototipe Pengaruh Sudut Kemiringan Poros Baling-Baling Terhadap Daya Dorong Kapal Laut (online). Jurnal V-Mac, Vol 2 No 1:18-24, 2017, ISSN 2528-0112.

[3] Aulia Windyandari, Dedy Wahyudi, 2011. Methodology Of The Hybrid Propulsion System (DPM \& DEP) For Trimaaran Type Fast Patroli Boat. Kapal-Vol. 8, NO. 3 Oktober 2011.

[4] Budi Utomo, 2012. Peranan Baling-Baling Pada Gerakan Kapal (Online). Jurnal Vol. 33 No.2 Tahun 2012, ISSN 0852-1697.

[5] Carlton, J, 2012. "Marine Propellers and Propulsion", 3rd edition, Elsevier.

[6] Couser, P R, Molland, A, F, Amstrom N And Utama, I K A P. 1997. Calm Water Powering Prediction For High Speed Catamaran, Procs. Of FAST 1997, Sydney, 21-23 July.

[7] Dimas Bagus Darmawan, Deddy Chrismianto, Muhammad Iqbal, 2016. Analisa Pengaruh Kemiringan HUB Propeller Tipe B-Series Pada Kapal Selam Tipe Menengah Untuk Mengoptimalkan Kinerja Kapal Selam Dengan Metode CFD (online). Jurnal Teknik Perkapalan - Vol. 4, No, 2 April 2016.

[8] Djatmiko et.al. 1983. Tahanan Penggerak Kapal. Jakarta: departemen pendidikan dan kebudayaan.

[9] D. J. Acheson (oxford, 2003). Elementary Fluid Dynamics.

[10] Dwi setiya ningsih, 2015. Rumus Trigonomeri.

[11] Eduart Wolok, Alfi SR Baruadi, Stella Junus, ZC Fachurssyah, 2016. Perahu Tradisional Ketinting (online). ISBN 978602-72985-2-1.

[12] Elymart jastro, FIB UI, 2010. Kajian Perahu Tradisional Nusantara Di Museum Bahari, jakarta utara.

[13] Fyson J. 1985. Design of Small Fishing Vessels.England: Fishing News Book. Pages: 2153.

[14] Harvald, Sv.Aa.,1978. Trust Deduction Estimation Of Harvald For Single-Screw
Ships. Estimation of power ship. ISP 25(283)

[15] Harvald, A, 1988. Tahanan dan Propulsi Kapal.Airlangga Press, Surabaya.

[16] Harvald, A. A. 1992. Tahanan dan Propulsi kapal. Surabaya: erlangga.

[17] Hans Otto Kristensen, Marie Lützen, 2013. Prediction of resistance and propulsion power of ships, Technical University of Denmark.

[18] Hogben, N dan Standing, R (1975) Wave Pattern Resistance From Routine Model Test, Trans. RINA, Vol.117.

[19] Ied Habibie, Mucthar Ahmad, Nofrizal 2010. Teknik Pemasangan Mesin Untuk Kapal Perikanan. Jurnal PERIKANAN dan KELAUTAN 15,1(2010)132-144.

[20] ITTC 1975, 14th International Towing Tank Conference. Form factor according to Prohaska.

[21] KBBI, 1991. Kamus Besar Bahasa Indonesia Edisi Kedua. Jakarta: Balai Pustaka.

[22] Lewis, Edward.V ,1988. "Principles of NavalArchietecture Second Revision" The Society ofNaval Architects and Marine Engineers 601Pavonia Avenue Jersey City, NJ.

[23] Liebner, horst H. 2005. "Perahu-Perahu Tradisional Nusantara Suatu Tinjauan Sejarah Perkapalan Dan Pelayaran" Dalam Eksplorasi Sumberdaya Budaya Maritim Oleh Edi Sedyawati (ed.), Hal. 53123. Jakarta:Departement Kelautan Dan Perikanan RI.

[24] Masroeri, A. A., \& Asianto. (1999). Diktat Perancangan Kamar Mesin. In A. A. Masroeri, \& Asianto, Diktat Perancangan Kamar Mesin. Surabaya: Institut Taknologi Sepuluh November.

[25] M. Rusydi Alwi, Syerly Klara \& M. Amril Idrus (JRTK), 2013.Unjuk Kerja Mesin Diesel Mitsubishi 4DRS Sebagai Penggerak Kapal Pada Kondisi Trim (online). Jurnal Voume 11, Nomor 1, Januari-Juni 2013.

[26] Molland, F.A., Turnock, R.S., \& Hudson, A.D. (2011), Ship Resistance and Propulsion: Practical Estimation Of Ship Propulsive Power. New York: Cambridge University Press.

[27] PERATURAN DIREKTUR JENDERAL PERIKANAN BUDIDAYA NOMOR 284. Petunjuk Teknis Pemberian Bantuan Mesin Tempel Perahu Jukung Kabupaten Rote 
Ndao Provinsi Nusa Tenggara Timur Tahun 2018.PER-DJPB / 2018.

[28] Sayyid Sabiq, Fis Purwangka, Yopi Novita, 2018. Intensitas Kebisingan Mesin Serbaguna Pada Perahu Gillnet Di Pangkalan Pendaratan Ikan Pangandaran. Jurnal Ilmiah Samudra Akuatika (2018), Vol, 2(2),9-21.
[29] Sukendar. (2002). Perahu Tradisional Nusantara, Jakarta: Pusat PenelitianArkeologi Badan Pengembangan Kebudayaan dan Pariwisata DeputiBidang Pelestarian dan Pengembangan Budaya.

[30] Utomo, bambang budi (ed). 2007. Pandanglah Laut Sebagai Pemersatu Nusantara. Jakarta: Departemen Kebudayaan Dan Pariwisata RI. 